\title{
Pemberdayaan Kader OSIS Sebagai Bentuk Preventif Bullying pada Remaja di Sekolah
}

\author{
Firsty Oktaria Grahani ${ }^{1}$, Aironi Zuroida ${ }^{2}$, Bergitha Dhei ${ }^{3}$ \\ ${ }^{123}$ Universitas Wijaya Putra
}

oktaria@uwp.ac.id, aironizuroida@uwp.ac.id, brigittadhei@gmail.com

\begin{abstract}
Abstrak
Penanganan untuk pencegahan munculnya bullying yang selama ini dilakukan masih kurang efektif. Maka perlu dilakukan psikoedukasi yang dalam hal ini dengan memberdayakan siswa-siswi yang terlibat dalam OSIS yang nantinya dapat menjadi kader dalam pencegahan terjadinya kasus bullying di lingkungan sekolah. Permasalahannya, yaitu pemberdayaan OSIS sebagai agent of bullying prevention belum efektif, kurangnya pemahaman masing-masing siswa yang menjadi anggota OSIS tentang dinamika bullying; kurangnya kepekaan dari siswa (anggota OSIS) terhadap lingkungannya, sehingga jika ada perilaku yang kurang tepat seperti membentak, mendorong bahkan mungkin memukul teman masih dianggap wajar, minimnya edukasi yang dilakukan oleh pihak sekolah terkait bullying. Tujuannya yaitu para kader OSIS memahami dinamika bullying, dapat menjadi agent of bullying prevention yang efektif di lingkungan sekolah, termotivasi untuk mencegah terjadinya kekerasan dalam wujud apapun di lingkungan sekolah, mampu merancang kegiatan-kegiatan yang berkaitan dengan psikoedukasi bullying terhadap seluruh siswa bahkan warga sekolah. Metode pelaksanaan yang digunakan dalam program ini melalui psikoedukasi, pelatihan diantaranya memberikan pemahaman mengenai dinamika bullying terkait karakteristik, jenis, faktor pemicu, dampak, dll, merancang workbook yang dapat digunakan kader OSIS sebagai guideline dalam melakukan psikoedukasi kepada siswa dan warga sekolah. Hasilnya beberapa siswa lebih memahami dinamika bullying secara detail terutama terkait efek yang ditimbulkan sehingga lebih peka terhadap sekelilingnya.
\end{abstract}

Kata Kunci : OSIS, preventif, bullying, remaja, sekolah

\section{PENDAHULUAN}

Perilaku bullying masih menjadi fenomena terjadinya kekerasan dalam kehidupan sehari-hari terutama di lingkungan sekolah bahkan hingga setahun terakhir. Sederet kasus bullying atau perundungan yang terjadi di sejumlah sekolah di Indonesia beberapa bulan terakhir seharusnya menjadi perhatian khusus yang harus segera ditindak lanjuti. Seperti kejadian yang terjadi di bulan November 2019 pada salah satu siswa SMA di Riau yang mengalami patah tulang hidung setelah menjadi korban bullying temannya dan yang terbaru pada bulan Februari 2020 pada salah satu siswa di SMPN Malang yang harus melakukan amputasi pada jari tengah tangan kanan setelah menjadi korban bullying dari tujuh orang temannya (Kompas, 2020).
Bullying adalah bentuk-bentuk perilaku kekerasan dimana terjadi pemaksaan secara psikologis ataupun fisik terhadap seseorang atau sekelompok orang yang lebih "lemah" oleh seseorang atau sekelompok orang. Pelaku bullying yang biasa disebut bully bisa seseorang, bisa juga sekelompok orang, dan ia atau mereka mempersepsikan dirinya memiliki power (kekuasaan) untuk melakukan apa saja terhadap korbannya. Korban juga mempersepsikan dirinya sebagai pihak yang lemah, tidak berdaya dan selalu merasa terancam oleh bully. (Jurnal Pengalaman Intervensi Dari Beberapa Kasus Bullying, Djuwita, 2005 ; 8, dalam Ariesto 2009).

Berikut data mengenai kasus bullying dari beberapa negara yang terjadi di sekolah. Berdasarkan penelitian L.K lee, P.C Chen, K.K lee, J. Kaur, dalam Arya, 2018 menyatakan jika 27,9 \%

$$
\text { Pendidikan }
$$


siswa terlibat perkelahian dan $5,9 \%$ terluka akibat perkelahian, $7,3 \%$ membawa senjata, $18,5 \%$ merasa tidak nyaman di sekolah, 55\% kehilangan uang dan barang berharga. Kemudian hasil penelitian lain yang dilakukan oleh Kann L., McManus T., Harris A. dkk, dalam Arya, 2018 menjelaskan bahwa $16,2 \%$ siswa membawa senjata, 5,3\% siswa membaca pistol, 6\% siswa mendapat ancaman dengan senjata dan pistol, $22,6 \%$ siswa terlibat perkelahian, $15,5 \%$ siswa telah dibully di dunia maya. Sementara itu di Indonesia juga telah banyak peneltian yang dilakukan berkaitan dengan tindak bullying seperti yang dilakukan oleh Saptandari, 2007 dalam Arya, 2018 yang menyampaikan bahwa berdasarkan kuisioner terhadap 37 orang guru yang terdiri dari delapan guru SD, delapan guru SMP, 12 guru SMA, dan sembilan guru SMK, menunjukkan bahwa sebanyak 89,2\% guru mengetahui atau pernah mendapat laporan bahwa bullying terjadi di sekolah tempat para guru tersebut mengajar. Kemudian penelitian lain yang dilakukan oleh Ratna Juwita di beberapa SMP dan SMA di Jakarta, Surabaya, dan Yogyakarta menunjukkan bahwa kasus bullying ditemukan pada 70,65\% SMP dan SMA di Yogyakarta, lebih tinggi daripada kasus di Jakarta dan Surabaya (Suyatno, 2008 dalam Arya, 2018)

Berdasarkan beberapa data yang telah dipaparkan di atas dapat diamati jika prosentase jumlah kasus bullying mengalami peningkatan dari tahun ke tahun dan banyak terjadi di lingkungan sekolah, maka dapat dikatakan jika penanganan untuk pencegahan munculnya perilaku bullying yang selama ini dilakukan terutama di sekolah dirasakan masih kurang efektif sehingga setiap tahun masih terjadi peningkatan kasus bullying di sekolah seperti yang disampaikan oleh KPAI behwasannya selama kurun waktu sembilan tahun terakhir sejak 2011 hingga 2019 ada sekitar 37.381 pengaduan kekerasan terhadap anak yang terjadi baik di lingkungan pendidikan maupun sosial dan terjadi peningkatan tiap tahunnya (www.kpai.go.id). Oleh karena itu perlu dilakukan psikoedukasi pada siswa-siwi yang dalam hal ini dilakukan dengan memberdayakan siswa-siswi yang terlibat dalam OSIS yang nantinya dapat menjadi kader dalam pencegahan terjadinya kasus bullying di lingkungan sekolah. Hal ini dengan memperhatikan usia remaja dimana individu memasuki masa pencarian jati diri dan peer group yang membawa pengaruh lebih besar pada diri dibanding orang lain.

\subsubsection{Profil Mitra : Sekolah Wijaya Putra}

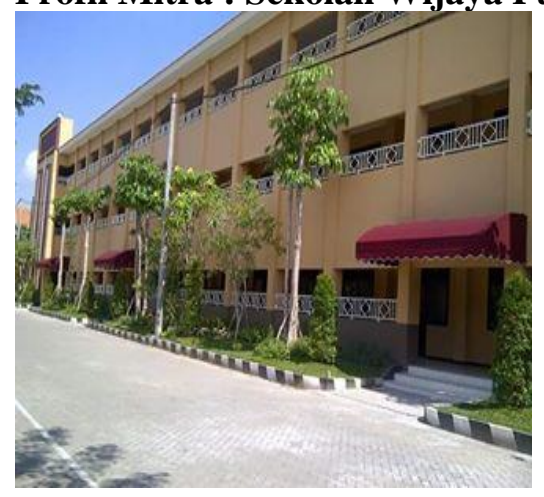

Sekolah Wijaya Putra berdiri pada tahun 1990. Sekolah Wijaya Putra memiliki tiga jenjang pendidikan yaitu SMP Wijaya Putra yang berdiri tahun 1998; SMA Wijaya Putra berdiri tahun 1993; SMK Wijaya Putra berdiri tahun 2000. Sebagai lembaga formal di bawah naungan Yayasan Insan Indonesia Mandiri, Sekolah Wijaya Putra sadar akan pentingnya pendidikan yang bermutu, baik dari segi intelektual maupun perilaku peserta didik, sebagaimana yang diamanatkan dalam UU sisdiknas no. 3 tahun 2003 yakni tujuan pendidikan nasional adalah membentuk manusia yang berkarakter oleh sebab itu selaras dengan tujuan sekolah Wijaya Putra mulai tahun pelajaran 2005 telah melaksanakan pendidikan budi pekerti. Dengan demikian sekolah wijaya putra dalam melaksanakan pendidikan memilki 3 (tiga) orentasi yang di terapkan dan di integrasikan ke dalam seluruh proses pendidikan dan pengajaran, yang terdiri dari Orentasi intelektual, orentasi komunikatif dan orentasi kebangsaan (berbudi pekerti luhur).

Anggota OSIS sekolah Wijaya Putra berdasarkan catatan yang diperoleh dari pembina OSIS di masing-masing jenjang sekolah terdiri dari 
Tabel 1. Data Anggota OSIS Sekolah Wijaya Putra

\begin{tabular}{|c|c|c|c|c|}
\hline No. & Jenjang & $\begin{array}{c}\text { Laki- } \\
\text { laki }\end{array}$ & Perempuan & Jumlah \\
\hline 1. & SMP & 10 & 14 & 24 \\
\hline 2. & SMA & 14 & 22 & 36 \\
\hline 3. & SMK & 16 & 17 & 33 \\
\hline \multicolumn{5}{|c|}{ Jumlah } \\
\hline
\end{tabular}

Aktivitas yang dilakukan oleh anggota OSIS Sekolah Wijaya Putra mulai dari jenjang SMP hingga SMA dan SMK :

a. Melibatkan siswa pada kegiatan proses penerimaan siswa baru.

b. Melibatkan siswa pada kegiatan peringatan hari besar.

c. Melibatkan siswa pada pentas seni baik yang dilakukan pada internal maupun eksternal sekolah.

d. Melibatkan siswa pada kegiatan promosi sekolah.

e. Mengikutsertakan siswa pada olimpiade sains, dsb.

\subsection{Permasalahan Mitra}

Berdasarkan kondisi objektif sebagaimana terurai dalam analisis situasi di atas, maka permasalahan mendasar yang dihadapi mitra dalam preventif bullying di sekolah dapat diklasifikasikan dalam tiga aspek. Pertama aspek kognitif, yaitu minimnya pemahaman akan pentingnya pencegahan bullying pada seluruh warga sekolah baik di level guru maupun siswa sehingga prioritas pengembangan skill selama ini lebih ke hard skill; pemberdaayan kader OSIS sebagai media pencegahan bullying yang cukup efektif karena faktor "peer group" yang kuat belum dipahami sehingga selama ini aktivitas pengembangan siswa lebih diprioritaskan pada pengembangan hard skill. Kedua aspek afektif, yaitu kurangnya pemahaman akan pentingnya tindakan preventif terhadap munculnya bullying di sekolah membuat kurangnya kepekaan dari siswa (anggota OSIS) terhadap lingkungannya; self awarenees dan kepekaan (empati) masing-masing anggota OSIS belum dikembangkan dengan optimal sehingga jika ada perilaku siswa yang kurang tepat seperti membentak, mendorong bahkan mungkin memukul teman masih dianggap wajar. Ketiga, aspek psikomotor, yaitu belum adanya pembekalan khusus semacam psikoedukasi (seminar berkaitan dengan bullying dan dinamikanya) yang diberikan pada siswa khususnya kader OSIS dalam membantu sekolah mencegah munculnya perilaku bullying; karena minimnya pemahaman dan kepekaan tentang pentingnya pencegahan perilaku bullying di sekolah maka selama ini belum ada program khusus yang diinisiasi oleh kader OSIS berkaitan dengan preventif; Jika terjadi tindak bullying seperti siswa membentak, mengejek, body shaming pada siswa lain cenderung diabaikan (tidak ada tindakan yang dilakukan).

\section{SOLUSI DAN TARGET LUARAN}

Permasalahan yang terjadi pada mitra terbagi menjadi tiga aspek sebagai berikut :

1. Aspek kognitif, yaitu minimnya pemahaman akan pentingnya pencegahan bullying pada seluruh warga sekolah baik di level guru maupun siswa. Solusi yang dilakukan adalah dengan pemberian prepost tes untuk melihat sejauh mana pemahaman yang dimiliki siswa tentang bullying; memberikan psikoedukasi berupa pemahaman terkait bullying dan dinamikanya serta penyampaian tahapan perkembangan masa remaja hingga dewasa awal berkaitan dengan peer group. Target luaran yang diharapkan, yaitu peningkatan pemahaman mengenai dinamika bullying; para kader OSIS paham bahwasannya mereka merupakan agent of bullying prevention yang efektif karena peer group.

2. Aspek afektif, yaitu pemahaman yang masih minim terkait bullying membuat kepekaan/ awareneess yang dimiliki para siswa terkait bullying belum berkembang dengan baik. Solusi yang dilakukan adalah melalui pemutaran film/video yang tentang bullying; studi kasus tentang bullying. Target luaran yang diharapkan peningkatan awareness para kader OSIS terkait bullying sehingga lebih tanggap dengan kondisi sekitarnya; para kader OSIS termotivasi untuk mencegah terjadinya kekerasan dalam wujud apapun di lingkungan sekolah.

3. Aspek psikomotor, yaitu kurangnya edukasi dan pemahaman terkait bullying sehingga 
kegiatan sosialisasi maupun aktivitas riil untuk mencegah munculnya bullying belum dilakukan. Solusi yang dilakukan menyusun work book tentang bullying, kasus-kasus bullying dan penanganannya bersama dengan kader OSIS; mengajak anggota OSIS untuk merancang kegiatan OSIS dengan menyertakan psikoedukasi pencegahan bullying dalam agenda tahunan kegiatannya serta berkoordinasi dengan pembina OSIS untuk penerapannya. Target luaran yang diharapkan adalah menjadikan psikoedukasi pencegahan bullying menjadi salah satu agenda kegiatan OSIS setiap tahunnya, pembuatan workbook oleh kader OSIS yang nantinya akan diberikan bersama dengan modul psikoedukasi bullying sehingga dapat lebih efektif dalam penerapan psikoedukasi dalam mencegah bullying kepada siswa-siswa yang lain pada sekolah mitra dan dapat menginisiasi psikoedukasi oleh Kader OSIS sekolah yang lain.

\section{METODE}

Adapun langkah-langkah pelaksanaan program pengabdian masyarakat ini adalah sebagai berikut:

1. Koordinasi dengan mitra terkait jadwal dan tempat pelaksanaan pelatihan.

Sasaran program pelatihan adalah siswa-siswi yang terlibat dalam OSIS mulai dari jenjang SMP, SMA hingga SMK yang masing-masing diwakili oleh enam siswa yang berada pada divisi budi pekerti dan sosial. Sedianya pelatihan akan dilakukan di tempat mitra namun, karena kondisi pandemi covid-19 dimana siswa-siswi sekolah diliburkan maka pelatihan dilakukan secara online melalui media zoom dan WA

2. Persiapan pelatihan.

Persiapan mencakup persiapan bahan materi bagi kader OSIS, pembuatan modul pembuatan instrument penilaian berupa kuisioner yang akan dibagikan sebelum dan sesudah pelatihan.

3. Pelaksanaan psikoedukasi.

Psikoedukasi dilaksanakan dengan pendekatan partisipatif dimana tim pengusul akan menyampaikan materi secara online kepada para kader OSIS selama beberapa pertemuan.
Setiap pertemuan menargetkan capaian bagi para kader OSIS hingga pada pertemuan terakhir Kader OSIS memahami dinamika bullying secara detail, memiliki kepekaan yang lebih tinggi terhadap sekitar dan mampu mengaplikasikan hasil psikoedukasi yang telah diperoleh menjadi bagian dari agenda kegiatan rutin OSIS dalam mencegah bullying di sekolah, mampu merancang work book yang digunakan sebagai panduan dalam pelaksanaan kegiatan preventif bullying pada mitra dan juga dikoordinasikan dengan pembina OSIS.

Proses psikoedukasi yang dilakukan diharapkan dapat berjalan efektif agar para kader OSIS yang nantinya menjadi agent of bullying prevention dapat memperoleh pengetahuan, pengalaman dan mengalami perubahan baik dari sisi kognitif, afektif dan psikomotor sehingga mampu menerapkan psikoedukasi sebagai metode preventif bullying menjadi salah satu agenda kegiatan rutin OSIS dan work book yang telah dirancang dapat menjadi panduan bagi siswa dalam pencegahan terjadinya bullying pada remaja serta dapat menginisiasi OSIS dari sekolah lain.

4. Evaluasi Proses Pelatihan

Hasil kuisioner diolah dan dianalisa untuk diketahui hasil akhir dari pelatihan apakah sesuai dengan yang diharapkan. Evaluasi ini berguna untuk pelatihan-pelatihan selanjutnya di program pengabdian yang lain, dan berguna juga untuk memberi tambahan informasi yang mungkin belum tersampaikan selama pelatihan kepada mitra.

5. Pemberian modul psikoedukasi pencegahan bullying untuk kader OSIS.

Tim pengusul akan memberikan modul psikoedukasi preventif bullying di sekolah bagi para kader OSIS untuk mempermudah pemahaman kader OSIS dan penerapan psikoedukasi pada sekolah masing-masing.

6. Penyusunan work book bersama dengan kader OSIS yang nantinya dapat digunakan bersamaan dengan modul dalam setiap pemberian psikoedukasi baik di lingkungan 
internal mitra maupun eksternal.

7. Pembuatan jurnal ilmiah dan laporan akhir.

Sebagai luaran wajib program pengabdian ini maka kami akan membuat jurnal ilmiah dan laporan akhir ketika semua program telah selesai dilaksanakan.

Setelah psikoedukasi ini selesai diharapkan kader OSIS mendapat manfaat berupa pengetahuan dan wawasan mengenai bullying dan dinamikanya sehingga diharapkan nantinya para kader tersebut dapat menjadikan psikoedukasi preventif bullying menjadi bagian dari agenda kegiatan tahunan OSIS kemudian dapat menggunakan work book yang disusun bersama dan modul yang diberikan sebagai panduan dalam penerapannya dalam lingkungan internal mitra dan menginisiasi OSIS sekolah lain untuk melakukan kegiatan yang sama agar dapat mengurangi terjadinya tindak bullying pada remaja di sekolah.

\section{HASIL DAN PEMBAHASAN}

Berdasarkan alternatif solusi yang telah disepakati bersama dengan mitra, maka telah dilaksanakan pemberdayaan kader OSIS sebagai bentuk preventif bullying pada remaja di sekolah dalam bentuk pemberian psikoedukasi yang dilakukan secara online dikarenakan kondisi pandemi covid-19. Pelatihan ini diberikan kepada 18 siswa yang menjadi anggota OSIS dan masuk dalam divisi sosial dan budi pekerti. Dalam hal ini masing jenjang pendidikan diwakili oleh 6 siswa Dengan rincian tahapan psikoedukasi sebagai berikut:

Tabel 2. Rincian Pelatihan

\begin{tabular}{|c|c|c|c|}
\hline No. & Tanggal & Aspek & Aktivitas \\
\hline 1. & $\begin{array}{c}8 \\
\text { Agustus } \\
2020\end{array}$ & Kognitif & $\begin{array}{l}\text { 1. Post-test } \\
\text { 2. Penyampaian } \\
\text { data-data riil } \\
\text { mengenai } \\
\text { fenomena } \\
\text { bullying yang } \\
\text { terjadi } \\
\text { 3. Sharing mengenai } \\
\text { perilaku bullying } \\
\text { yang sering } \\
\text { ditemui di } \\
\text { lingkungan } \\
\text { sekolah dan }\end{array}$ \\
\hline
\end{tabular}

seberapa penting tindak bullying untuk ditangani.

\begin{tabular}{|c|c|c|c|}
\hline & & & $\begin{array}{l}\text { seberapa penting } \\
\text { tindak bullying } \\
\text { untuk ditangani. }\end{array}$ \\
\hline 2. & $\begin{array}{c}10 \\
\text { Agustus } \\
2020\end{array}$ & Kognitif & $\begin{array}{l}\text { 1. Review materi } \\
\text { sebelumnya dan } \\
\text { penyampaikan } \\
\text { materi tentang } \\
\text { definisi bullying, } \\
\text { perbedaan } \\
\text { bullying dan } \\
\text { agresi. }\end{array}$ \\
\hline
\end{tabular}

2. Pemutaran video layanan masyarakat mengenai bullying, jenisjenisnya dan dampak bullying.

3. Sharing mengenai video yang telah dilihat.

1. Review materi yang disampaikan di pertemuan sebelumnya

2. Penjelasan mengenai faktorfaktor penyebab bullying, tahapan perkembangan remaja, alasan OSIS dapat menjadi agent of bullying prevention. Jenis-jenis bullying

3. Sharing mengenai jenisjenis bullying berdasarkan amatan para peserta, tindakan sekolah dan peserta sendiri ketika melihat tindak bullying. 


\begin{tabular}{|c|c|c|c|}
\hline 4 & $\begin{array}{c}14 \\
\text { Agustus } \\
2020\end{array}$ & $\begin{array}{l}\text { Kognitif } \\
\text { Afektif } \\
\text { Psikomotor }\end{array}$ & $\begin{array}{l}\text { 1. Studi kasus } \\
\text { (Identifikasi } \\
\text { jenis-jenis tindak } \\
\text { bullying, kasus- } \\
\text { kasus bullying } \\
\text { yang terjadi di } \\
\text { sekolah). } \\
\text { 2. Penjelasan } \\
\text { mengenai } \\
\text { dampak-dampak } \\
\text { bullying. } \\
\text { 3. Posttest } \\
\text { 4. Sharing } \\
\text { kontribusi yang } \\
\text { diberikan untuk } \\
\text { ke depan dalam } \\
\text { mengurangi } \\
\text { berkembangnya } \\
\text { perilaku bullying } \\
\text { di sekolah }\end{array}$ \\
\hline 5. & $\begin{array}{c}18,19, \\
22,24 \\
\text { Agustus } \\
2020\end{array}$ & $\begin{array}{l}\text { Kognitif, } \\
\text { Afektif, } \\
\text { Psikomotor }\end{array}$ & $\begin{array}{l}\text { Merancang dan } \\
\text { membuat work } \\
\text { book } \\
\text { Psikoedukasi } \\
\text { bersama dengan } \\
\text { Kader OSIS agar } \\
\text { dapat } \\
\text { memudahkan } \\
\text { penerapan } \\
\text { psikoedukasi } \\
\text { terhadap siswa } \\
\text { yang lain. }\end{array}$ \\
\hline
\end{tabular}

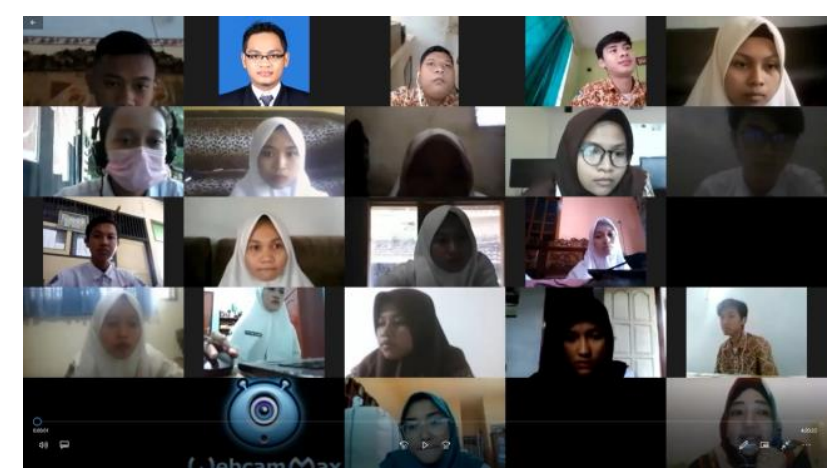

Gambar 1. Pelatihan yang dilakukan dengan media zoom

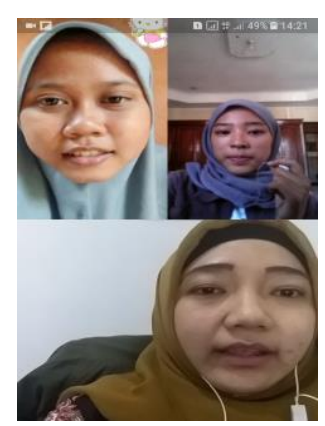

Gambar 2. Aktivitas yang dilakukan dengan media Video Call Group

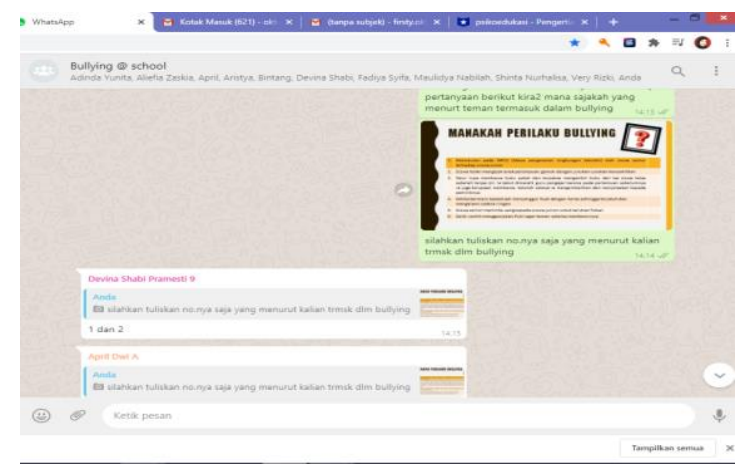

Gambar 3. Aktivitas yang dilakukan dengan media WAG

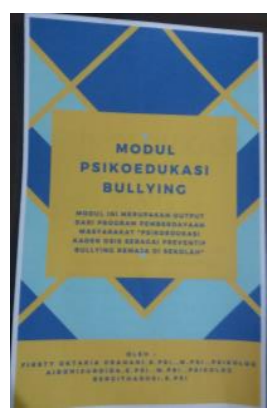

Gambar 4. Modul Psikoedukasi Bullying

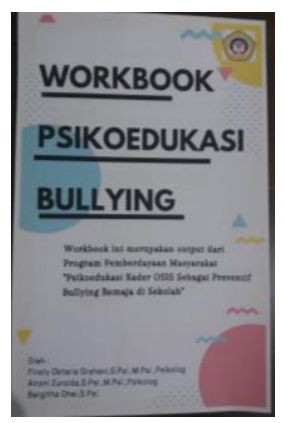

Gambar 5. Workbook Psikoedukasi Bullying 
Berdasarkan hasil psikoedukasi yang telah dilakukan diperoleh bahwa beberapa kader OSIS yang terlibat sebagai peserta sebenarnya telah memahami tentang bullying dan dinamikanya namun, pehamanan yang mereka miliki belum detail sehingga turut mempengaruhi awareness yang mereka miliki terhadap kondisi sekitarnya, maka dari itu ketika melihat terjadi tindak bullying beberapa dari mereka ada yang hanya diam saja tetapi ada yang hanya sekedar menegur pelaku. Untuk melihat efektivitas pemberian psikoedukasi proses evaluasi dilakukan berdasarkan Four Level Evaluation Model (Kirkpatrick, 2008) yaitu level reaction dengan mengamati antusiasme peserta selama mengikuti psikoedukasi yang tampak dari kecepatan respon dan kontribusi aktif yang diberikan selama proses psikoedukasi meskipun dilakukan secara online. Kemudian level learning yang dapat diamati dari hasil prepost-test yang diberikan, dimana para peserta lebih memahami secara detail mengenai perbedaan bullying dengan agresi, jenis-jenis bullying dan dampaknya. Mereka juga menyampaikan harapan ke depan terkait penerapan psikoedukasi yang telah diperolehnya. Pada level behavior, yaitu bersama kader OSIS merancang dan membuat workbook psikoedukasi bullying yang nantinya dapat digunakan sebagai pendamping dari modul ketika para kader OSIS memberikan psikoedukasi pada siswa-siswa yang lain sekaligus dapat juga digunakan sebagai media dalam menyampaikan pentingnya pencegahan bullying remaja di sekolah kepada kader OSIS dari sekolah-sekolah yang berbeda. Pada level psikomotor berdasarkan hasil follow up yang dilakukan para Kader OSIS menyampaikan jika sementara waktu karena pandemi covid-19 dan sekolah masih dilakukan secara online pengaplikasian proses psikoedukasi bullying diterapkan di lingkungan sekitar para kader seperti lingkungan rumah, tetangga dan saudara terdekat.

Berdasarkan proses evaluasi yang telah dilakukan di atas harapannya psikoedukasi dan workbook edukasi bullying yang telah disusun tidak hanya diterapkan pada lingkungan internal saja tetapi dapat juga disampaikan pada sekolah-sekolah yang lain.

\section{KESIMPULAN}

Adapun kesimpulan dari seluruh rangkaian kegiatan ini adalah sebagai berikut :

1. Pemahaman terkait pentingnya pencegahan bullying khususnya di lingkungan sekolah masih kurang sehingga fokus penanganan yang dilakukan menjadi tidak optimal sehingga adanya kegiatan psikoedukasi dapat menjadi tambahan wawasan dan pengetahuan yang baru bagi warga sekolah khususnya bagi kader OSIS yang diharapkan dapat menjadi agent of bullying prevention di sekolah dengan turut serta berpartisipasi mengedukasi siswa-siswi yang lain.

2. Dengan diberikannya psikoedukasi kepada para kader OSIS diharapkan dapat meningkatkan awareness yang dimiliki sehingga dapat lebih tanggap ketika terjadi tindak bullying di lingkungan sekolah dalam wujud apapun.

3. Peningkatan pemahaman, awareness dan workbook yang telah disusun bersama kader OSIS diharapkan dapat memudahkan penerapan psikoedukasi pada siswa-siswa yang lain di lingkungan internal mitra.

4. Dapat menjadi sarana dalam menginisiasi sekolah-sekolah yang lain sehingga dapat mengurangi berbagai tindak bullying yang terjadi pada remaja di lingkungan sekolah. Harapannya jika psikoedukasi dalam pencegahan bullying dapat berjalan efektif di setiap sekolah melalui pemberdayaan Kader OSIS maka dapat menjadi wacana bagi sekolah untuk merancang kurikulum anti bullying sebagai salah satu bentuk lanjut dari pendidikan budi pekerti yang selama ini telah diterapkan.

\section{UCAPAN TERIMAKASIH}

Ucapan terimakasih disampaikan kepada Sekolah Wijaya Putra khususnya para siswa kader OSIS yang terlibat sebagai peserta dalam program Pemberdayaan Kader OSIS sebagai bentuk Preventif Bullying Pada Remaja di Sekolah atas kontribusi dan kerjasamanya selaku mitra.

Ucapan terimakasih disampaikan juga kepada Fakultas Psikologi Universitas Wijaya Putra dan

$$
\text { Pendidikan }
$$


LPPM atas dukungannya sehingga kegiatan ini dapat terlaksana dengan baik.

\section{REFERENSI}

Adiyanti, Saptandari. (2013). Mengurangi Bullying melalui Program Pelatihan "Guru Peduli". Jurnal Psikologi. Volume 40(2). 193-210.

Ariesto, Asdrian. (2009). Pelaksanaan Program Anti Bullying Teacher Emowerment Program di Sekolah. Skripsi Fakultas Sosial dan Ilmu Politik, Universitas Indonesia.

Arya, Lutfi. (2018). Melawan Bullying Menggagas Kurikulum Anti Bullying di Sekolah. Mojokerto: Penerbit Sepilar.

Davidoff, Linda, (1991). Psikologi Suatu Pengantar. Jakarta: Erlangga.

Kirkpatrick, D.L. \& Kirkpatrick, J.D. (2008). Evaluating Training Programs (Third edition PDF e-book ISBN 978-1-57675-796-3). San Fransisco: Berrett-Koehler Publisher.

Kurniati, Pythag. (2020). 4 Kasus Bullying di Sejumlah Daerah, Dibanting ke Paving, Amputasi hingga Korban Depresi Berat. www.kompas.com (diakses tanggal 5 Maret 2020).

Olweus,D. (2003). Bullying at school. USA:
Blackwell publishing.

Santoso, Humaedi, Zakiyah. (2017). Faktor yang Mempengaruhi Remaja dalam Melakukan Bullying. Jurnal Penelitan \& PPM. Vol 4(2). 129389.

Saribu. (2015). Tingkat Pemahaman Siswa terhadap Bullying pada Kelas IX SMPN 8 Cilacap. Skripsi Fakutas Ilmu Pendidikan. Universitas Negeri Yogyakarta.

Sullivan, H. O. (2011). Developing A School As A Professional Learning Community (PLC).

Tim KPAI. 2020. Sejumlah Kasus Bullying Sudah Warnai Catatan Masalah Anak di Awal 2020, Begini kata komisioner KPAI. https://www.kpai.go.id/berita/sejumlah-kasusbullying-sudah-warnai-catatan-masalah-anak-diawal-2020-begini-kata-komisioner-kpai 10 Februari 2020. Diunduh tanggal 13 Juli 2020.

Widiyantoro. 2020. Tak Cuma di Solo, 4 Kasus Bullying ini Bikin Gempar Bahkan Berakhir di Kepolisian. https://www.solopos.com/tak-cumadi-solo-4-kasus-bullying-ini-bikin-gempar-bahkanberakhir-di-kepolisian-1076012. Diunduh tanggal 13 Juli 2020. 